\title{
Thermal energy in dry snow avalanches
}

\author{
W. Steinkogler ${ }^{1,2}$, B. Sovilla ${ }^{1}$, and M. Lehning ${ }^{1,2}$ \\ ${ }^{1}$ WSL Institute for Snow and Avalanche Research SLF, Davos Dorf, Switzerland \\ ${ }^{2}$ CRYOS, School of Architecture, Civil and Environmental Engineering, EPFL, Lausanne, Switzerland
}

Correspondence to: W. Steinkogler (steinkogler@slf.ch)

Received: 24 September 2014 - Published in The Cryosphere Discuss.: 20 November 2014

Revised: 19 August 2015 - Accepted: 21 August 2015 - Published: 17 September 2015

\begin{abstract}
Avalanches can exhibit many different flow regimes from powder clouds to slush flows. Flow regimes are largely controlled by the properties of the snow released and entrained along the path. Recent investigations showed the temperature of the moving snow to be one of the most important factors controlling the mobility of the flow. The temperature of an avalanche is determined by the temperature of the released and entrained snow but also increases by frictional processes with time. For three artificially released avalanches, we conducted snow profiles along the avalanche track and in the deposition area, which allowed quantifying the temperature of the eroded snow layers. This data set allowed to calculate the thermal balance, from release to deposition, and to discuss the magnitudes of different sources of thermal energy of the avalanches. For the investigated dry avalanches, the thermal energy increase due to friction was mainly depending on the effective elevation drop of the mass of the avalanche with a warming of approximately $0.3{ }^{\circ} \mathrm{C}$ per 100 vertical metres. Contrarily, the temperature change due to entrainment varied for the individual avalanches, from -0.08 to $0.3^{\circ} \mathrm{C}$, and depended on the temperature of the snow along the path and the erosion depth. Infrared radiation thermography (IRT) was used to assess the surface temperature before, during and just after the avalanche with high spatial resolution. This data set allowed to identify the warmest temperatures to be located in the deposits of the dense core. Future research directions, especially for the application of IRT, in the field of thermal investigations in avalanche dynamics are discussed.
\end{abstract}

\section{Introduction}

Avalanches can exhibit many different flow regimes (Gauer et al., 2008) depending on (1) the released and entrained amount of snow, (2) the properties of the snow and (3) the topography (slope, curvature) (Naaim et al., 2013). Studies showed that avalanches can increase their mass due to entrainment by multiple factors (Sovilla et al., 2007; Bates et al., 2014) which in turn influences the run-out distance. Even though important, the amount of snow entrained is not the main controlling factor that determines the flow form of the avalanche (Bartelt et al., 2012). The flow regimes and in turn mobility are strongly influenced by the properties of the entrained snow (Steinkogler et al., 2014). Data on front velocities, run out, flow regimes and powder clouds revealed that different avalanches can form with similar release conditions and on the same avalanche path depending on the inherent snow cover properties. Advancements in avalanche dynamics models allow to account for the properties of the flowing snow with more and more detail (Vera Valero et al., 2015).

Recently, it has been shown that snow temperature inside an avalanche can significantly change its flow dynamics (Naaim et al., 2013; Steinkogler et al., 2014), mainly by changing the granular structure of the flow (Steinkogler et al., 2015). Laboratory studies on the granulation of snow showed a distinct dependency on snow temperatures with a fundamental change in snow structure at a threshold of $-1^{\circ} \mathrm{C}$. Therefore, significant changes in flow dynamics can be expected with relatively small changes in temperature around this threshold.

Measuring temperature inside a flowing avalanche or in its deposit with traditional methods has proven to be difficult due to technical constraints or because measurements cannot 


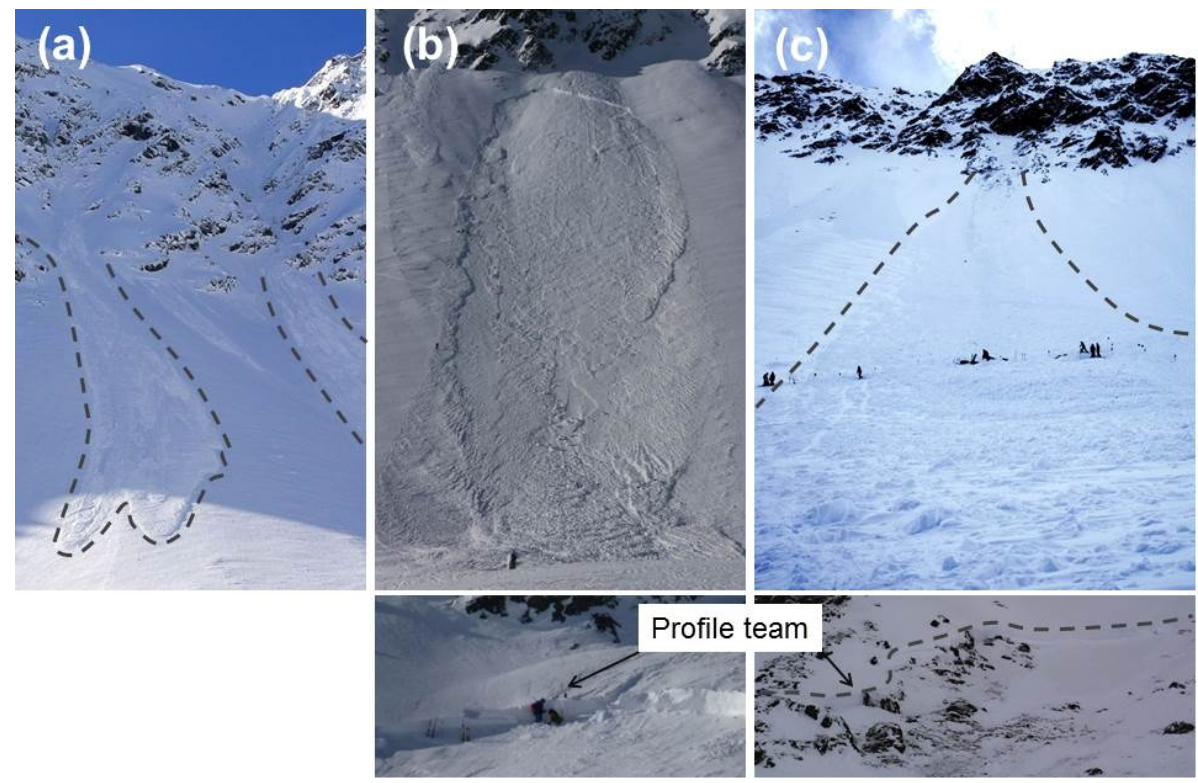

Figure 1. Avalanches at the Flüelapass field site released by artificial triggering of the cornices on the ridge. Avalanche \#1a and \#1b (a) were released on 23 January 2013, \#2 (b) on 5 February 2013 and \#3 (c) on 31 January 2014. Note the significant secondary release and entrainment of deeper layers below the rock face for (b) avalanche \#2 and (c) avalanche \#3.

be conducted due to safety reasons. In addition to manual snow profiles we therefore investigate the application potential of infrared radiation thermography (IRT) technologies. IRT is a non-contact, non-intrusive technique, which enables us to see surface temperature in a visible image. Meola and Carlomagno (2004) give an overview on existing work and describe the most relevant industrial and research applications of IRT.

The emissivity of a surface is a function of many factors, including water content, chemical composition, structure and roughness (Snyder et al., 1998) as well as the viewing angle between observer and measurement object. Even though many technical challenges and shortcomings of IRT are known, possible applications on the field of snow science have recently been discussed (Shea and Jamieson, 2011). Shea et al. (2012) and Schirmer and Jamieson (2014) applied IRT to measure spatial snow surface temperatures on snow pit walls. It was found that fast and large temperature changes resulting from surface energy balance processes must be expected (Schirmer and Jamieson, 2014). These energy balance processes between air and snow are particularly important during windy conditions, clear skies and large temperature differences between air and snow. These findings indicate that measuring the snow surface temperature of avalanche deposits or erosion layers along the track must be carried out as fast as possible. If IRT can therefore be seen as a useful qualitative or quantitative tool for snow applications still needs further verification.

The aim of this study is to identify the spatial temperature distribution in an avalanche and to quantify potential sources of thermal energy in an order of magnitude estimation. This is achieved by field measurements and the application of an IRT camera. A secondary aim is to evaluate the application of the IRT technique to get deeper insights into the thermal state of an avalanche.

\section{Methods and data}

\subsection{The Flüelapass field site}

Multiple dry avalanches were artificially released during winters 2012-13 and 2013-14 at the Flüelapass field site above Davos (Switzerland). Here we will discuss three avalanches, \#1 (23 January 2013), \#2 (5 February 2013) and \#3 (31 January 2014), out of this data base (Fig. 1).

The avalanche path is a north-east facing slope covering 600 vertical metres. Deposits of larger avalanches typically reach a lake located at $2374 \mathrm{~m}$ a.s.l. at the bottom of the slope (Fig. 2). Observations and remote measurements can safely be conducted from the road at the pass which is approximately $800 \mathrm{~m}$ away from the avalanche. The slope angle ranges from $50^{\circ}$ in the rock face in the upper part to $20^{\circ}$ at the beginning of the run-out zone with an average of $30^{\circ}$ of the open slope around $2600 \mathrm{~m}$ a.s.l.

\subsection{Snow profiles}

To assess the properties of the released and entrained snow, manual snow profiles according to Fierz et al. (2009) were conducted in the release zone $\left(P_{\text {release }}\right)$, i.e. just below the 


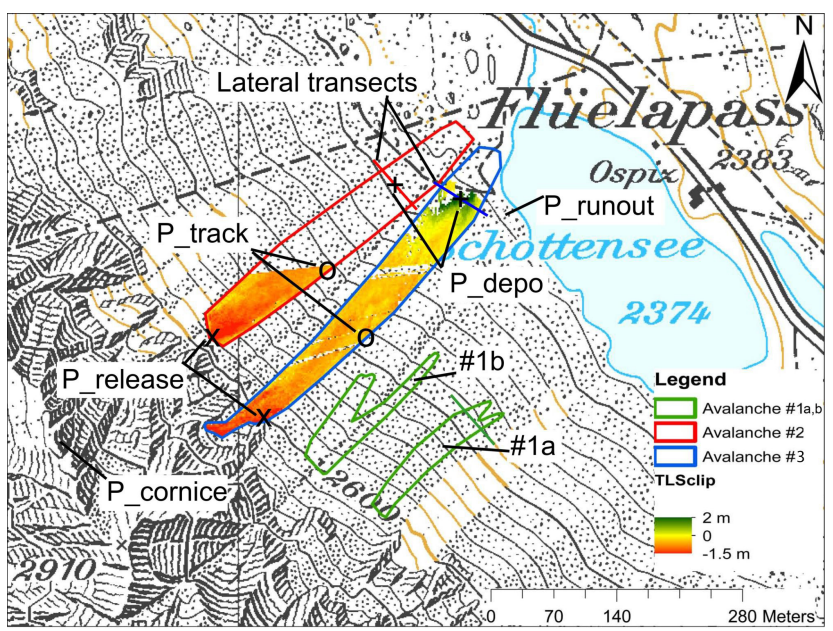

Figure 2. Flüelapass field site close to Davos (Switzerland). Outlines of avalanche \#1a and \#1b (green), \#2 (red) and \#3 (blue). The colour bar shows differences between terrestrial laser scans before and after the individual avalanches. $P_{\text {release }}$ and $P_{\text {track }}$ indicate locations of snow profile in the release and along the path, respectively. Red and blue lines indicate positions of lateral investigations and deposition snow profile $P_{\text {depo }}$.

rock face, along the track $\left(P_{\text {track }}\right)$, in the deposition zone $\left(P_{\text {depo }}\right)$ and in the undisturbed snow cover in the run out zone $\left(P_{\text {runout }}\right)($ Fig. 2). The profile location of the initially released cornice is refereed to as $P_{\text {cornice. In combination with release }}$ and erosion depths, the acquired snow profiles allowed to identify which layers were entrained into the avalanche.

All profiles were conducted as fast as possible after the avalanche stopped. Yet, especially for the profiles in the release area and the track, it took around $30 \mathrm{~min}$ to reach the profile locations. The temperature measurements close to the surface must therefore be interpreted carefully due to a rapid adaptation to the ambient conditions.

In addition to the acquired video and pictures of the powder cloud the deposits of the avalanche were investigated for indications of different flow regimes according to the observation criteria of Issler et al. (2008).

\subsection{Lateral temperature profiles}

In addition to the regular snow profiles, trenches were dug in the deposition zone and modified avalanche probes were used to measure lateral temperature gradients. The modified temperature probes (BTS probes) are regular avalanche probes for which the tip was replaced by a thermistor. BTS probes are usually used for permafrost applications (Lewkowicz and Ednie, 2004; Brenning et al., 2005) to measure the temperature at the interface between soil and snow. Their application allowed to measure the temperature of snow layers without exposing them to the ambient air temperature. As for the thermometers used for regular snow profiles (Sect. 2.2) they measure the snow temperature with an accuracy of $\pm 0.1^{\circ} \mathrm{C}$. As for the regular snow profiles the upper most layers need to be interpreted carefully in this investigation due to an expected change in temperature over time. The lateral temperature measurements were conducted from the left and right side towards the snow profile $P_{\text {depo }}$, which was situated in the centre of the deposition zone (Fig. 2), simultaneously. The BTS probe measurements were conducted with a vertical resolution of typically $30 \mathrm{~cm}$ and each individual measurement took around 3-5 min, giving the thermistor sufficient time to adapt to the snow temperature. In total these measurements took 1-2 h. Additionally, the snow depth of the deposits was determined by regularly spaced pits along the transect after the temperature measurements for avalanche \#3. For avalanche \#2 a full trench was dug were the measurements were performed.

\subsection{Infrared radiation thermography (IRT) camera}

The snow temperature measurements acquired from profiles where supplemented with an infrared radiation thermography (IRT) camera which allowed to record snow surface temperatures before, during and after the avalanche (Figs. 3 and 5). Time-lapse measurements after the avalanche stopped allowed to follow the temporal evolution of surface temperatures (Fig. 4) and videos of the moving avalanche provided a qualitative yet illustrative point of view (provided as Supplement). The first pictures were recorded as fast as possible (usually less than $1 \mathrm{~min}$ ) after the powder cloud disappeared and the video recording was stopped.

We used an InfraTec VarioCAM hr $384 \mathrm{sl}$ and a VarioCAM HD $980 \mathrm{~s}$ that both operate in the long wave infrared spectral range (LWIR) covering 7.5 to $14 \mu \mathrm{m}$. According to the manufacturer the cameras measure with an absolute accuracy of $\pm 1.5^{\circ} \mathrm{C}$ and a resolution of $0.05^{\circ} \mathrm{C}$. The measurements were either conducted with a 15 or $30 \mathrm{~mm}$ lens. With the used IRT cameras and lenses the pixel size of the footprint is approximately $1 \mathrm{~m}$ with the old camera and $0.5 \mathrm{~m}$ with the newer model. Since cold and dry atmospheric (determined by an automatic weather station close by) and snow conditions prevailed during avalanche experiments \#1 and \#2 an emissivity value of 1 has been chosen for all post-processing operations.

Even though in our study we use the IRT measurements mainly in a qualitative way, a basic verification was conducted.

The surface temperatures measured with the IRT camera (lines in Fig. 4) were compared to the corresponding manually measured temperatures (diamonds in Fig. 4) at the snow profile locations (Fig. 2). The release sliding surface temper-

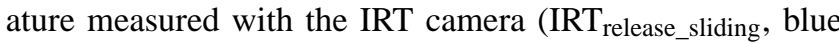
continuous line in Fig. 4) has been compared with the corresponding layer in the manual profile performed close to the release zone ( $T_{-} P_{\text {release_sliding }}$, blue full diamond at $\left.0 \mathrm{~min}\right)$. The avalanche sliding surface temperature measured with the IRT camera in the upper part of the track ( $I R T_{\text {track_sliding, }}$ orange continuous line in Fig. 4) has been compared with the 

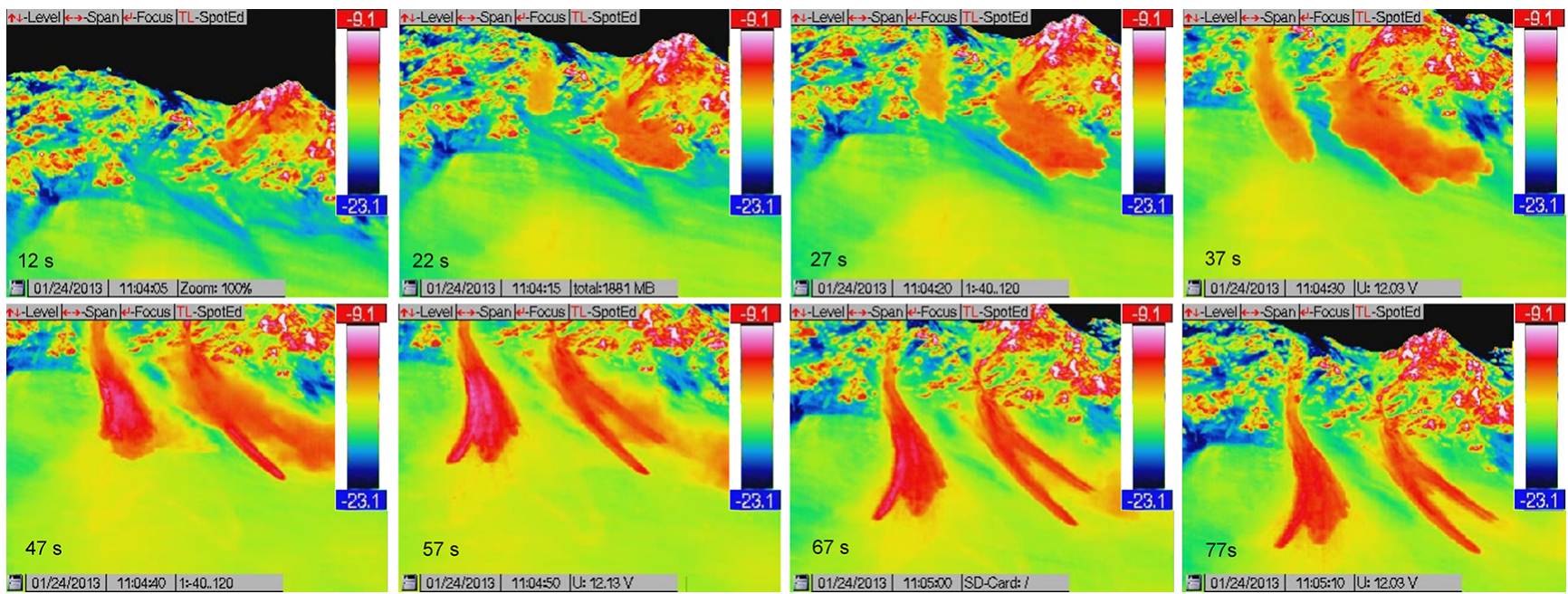

Figure 3. Screenshot of IRT camera videos for avalanche \#1a and \#1b. The first picture was taken $12 \mathrm{~s}$ after the avalanche released.

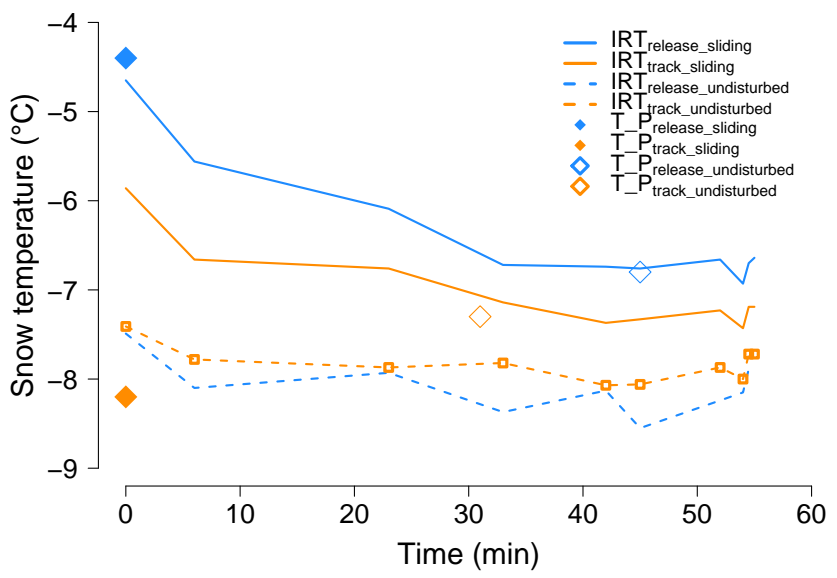

Figure 4. Temporal evolution and comparison of snow temperatures of avalanche \#2 using an IRT camera and manually measured data. Solid lines represent IRT measurements in the release (blue line) and track (orange line) sliding surfaces. Dashed lines represent IRT measurements performed in the undisturbed snow cover close to the release (blue) and close to the avalanche path (orange). Small dots on the orange dashed line correspond to the time resolution of all IRT measurements. Data from IRT are compared with manual measurements performed at the corresponding layer (filled diamonds) and at the snow surface (empty diamonds) at the closest snow profile.

corresponding layer in the manual profile performed close to the flowing zone ( $T_{-} P_{\text {track_sliding, }}$, orange full diamond). Further, the surface temperature of the undisturbed snow close to the snow profile location in the release and in the track (IRT $T_{\text {release_undisturbed }}$ and IRT $_{\text {track_undisturbed, }}$, blue and orange dashed lines) have been compared to snow surface temperature measurements at the profiles $\left(T_{-} P_{\text {release_undisturbed }}\right.$ and $T \_P_{\text {track_undisturbed }}$, empty diamonds). Measurements are in fairly good agreement with an absolute difference of about $\pm 1.5^{\circ} \mathrm{C}$ (except for $T \_P_{\text {track_sliding }}$ ). This accuracy suggests that the data cannot be used to quantify precise absolute temperature values, but to get an order of magnitude between relative differences.

\subsection{Terrestrial laser scan (TLS) and mass balance}

A terrestrial laser scanner (Riegl LPM-321) was operated from the Flüelapass road (Fig. 2) to acquire digital surface models before and after the avalanche releases. These measurements facilitated the calculation of the release, entrainment and deposition area. Furthermore, the difference between the two laser scans allowed to calculate the spatially averaged release and erosion depth along the path. The combination of area, release/erosion depth and depthaveraged snow density from the manually created snow profiles (Sect. 2.2) allowed to calculate the corresponding mass. Adding release and entrained mass results in the deposited mass. This procedure is common practice and was applied in multiple other studies (Sovilla et al., 2007, 2010; Steinkogler et al., 2014).

A complete set of terrestrial laser scans is available for avalanche \#3 only. For avalanche \#2 the scan before the avalanche is only available for the release zone (Fig. 2). No information from terrestrial laser scanning was available for avalanche \#1. Avalanche boundaries and field measurement locations were recorded by GPS allowing spatial referencing with the TLS data. A summer digital elevation model (DEM) was available from an airborne digital photogrammetry campaign (Bühler et al., 2015) with $1 \mathrm{~m}$ spatial resolution. It was mainly used to georeference our data and allow consequent processing in a GIS system. Furthermore, the summer DEM allowed to determine the topography below the lateral transects in the avalanche deposits (Sect. 2.3). 


\section{Investigated avalanches}

This section summarizes the key characteristics and available data (Table 1) of the avalanches. All avalanches were released after a snow storm by triggering the cornices at the ridge at $2900 \mathrm{~m}$ a.s.l. with explosives. Therefore, most of the released snow was new snow. Yet, two of the avalanches, avalanche \#2 and \#3 (Fig. 1b and c), entrained significant amounts of snow from deeper layers due to a secondary release in a deeper weak layer, below the rock face. Since the main mass contribution can be assumed to be defined by the secondary releases and the entrainment along the path, we focused our investigations on these snow masses. Mass contributions by the cornices are usually relatively small compared to entrained snow on the open slope below. Furthermore, entrainment of snow in the gullies of the rock face is not assumed to contribute a significant amount since regularly occurring (small) avalanches and slides continuously erode the snow cover. In this study we use the word release to refer to profile locations at the secondary release below the rock face (Fig. 2).

\subsection{Avalanche \#1a and \#1b (23 January 2013)}

In the days previous to the avalanche experiment $10 \mathrm{~cm}$ of new snow were recorded and snow drift accumulations formed due to strong southerly winds. The national avalanche bulletin reported a moderate avalanche danger (level 2) and identified the fresh snow drift accumulations as the main danger. During the experiment clear sky conditions prevailed and the automatic weather station (AWS) at the Flüelapass (FLU2) measured an air temperature of $-10^{\circ} \mathrm{C}$. Multiple charges were exploded on the ridge to the left (south) side, facing uphill, of the summit, resulting in two independent small powder avalanches which followed the gullies (Figs. 1a and 3). Due to the relatively small release mass and no significant entrainment, both avalanches, \#1a and \#1b, stopped halfway down the open slope. Even though the avalanches were small and a full data set of field measurements is not available, they are retained in this study since they provide good quality IRT data (Fig. 3). We excluded the snow profile measurements from the analysis since the erosion and deposition depths were very small, around $0.1 \mathrm{~m}$, and the manual measurements were conducted more than $1 \mathrm{~h}$ after the release. The deposition zone was not accessible before due to safety reasons. The TLS could not be completed due to technical problems.

\subsection{Avalanche \#2 (5 February 2013)}

$20 \mathrm{~cm}$ of fresh snow that covered older snow drift accumulations resulted in a considerable (level 3) avalanche danger. Furthermore, the bulletin noted that avalanches in isolated cases could be released deeper within the snowpack. The
Table 1. Summary of measurements for the investigated avalanches.

\begin{tabular}{llll}
\hline $\begin{array}{l}\text { Avalanche } \\
\text { Date }\end{array}$ & 23 Jan 2013 & 52 Feb 2013 & 31 Jan 2014 \\
\hline IRT camera model & h 384 sl & h 384 sl & HD 980 s \\
\hline Terrestrial laser scan & no & partly & yes \\
Snow profiles lateral & $-^{*}$ & yes & yes \\
Snow profiles track & $-^{*}$ & yes & yes \\
IRT video & yes & yes & no \\
IRT pictures & yes & yes & yes \\
\hline Released mass $m_{\mathrm{r}}(t)$ & - & 502 & 818 \\
Entrained mass $m_{\mathrm{e}}(t)$ & - & 1857 & 1302 \\
Deposited mass $m_{\mathrm{d}}(t)$ & - & 2359 & 2120 \\
\hline Growth index $I_{\mathrm{g}}$ & - & 3.7 & 1.6 \\
\hline *indicate that erosion and deposition depths were too small. Growth index $I_{\mathrm{g}}$ is defined as \\
$I_{\mathrm{g}}=m_{\mathrm{e}} / m_{\mathrm{r}}$.
\end{tabular}

AWS at Flüelapass measured $-12^{\circ} \mathrm{C}$ and a partly cloudy sky prevailed during the experiment.

Explosions along the ridge and to the observer's left (South) side of the summit only produced small avalanches that stopped shortly below the rock face. A single explosion that triggered the cornice to the right side of the summit caused another small powder avalanche that followed the gully and triggered a secondary release at the start of the open slope (Fig. 1b). Even though the avalanche almost stopped after entering the open slope, the additional mass which was entrained resulted in an re-acceleration resulting in a long running medium-sized avalanche (deposition mass $2357 \mathrm{t}$ ) which only stopped in the flat part close to the lake. Average snow density of the release was 170 and $210 \mathrm{~kg} \mathrm{~m}^{-3}$ for the entrained snow. No full TLS was available before the avalanche release. Nevertheless, in-field observations showed the surface before the release and the entrainment depth to be rather homogenous along the slope which allowed to extrapolate the upper entrainment area, in combination with the envelope of the avalanche acquired with GPS, and thus to calculate the entire entrained mass.

\subsection{Avalanche \#3 (31 January 2014)}

Multiple consecutive smaller snowfalls and strong southerly winds created snow accumulations close to ridges. The national avalanche bulletin issued a considerable (level 3) danger level and that the weak, old snowpack could cause avalanches to be released in near-ground layers. Moderate winds with gusts up to $60 \mathrm{~km} \mathrm{~h}^{-1}$ from the South and cloudy to overcast conditions prevailed during the experiment. The automatic weather station FLU2 recorded $-6^{\circ} \mathrm{C}$ with steadily increasing temperatures during the experiment.

Two small spontaneous avalanches already released before the experiment. Initial bombing of the main gully and to the observer's left (south) of the summit did not produce any significant avalanches. Yet, the bombing of the cornice 

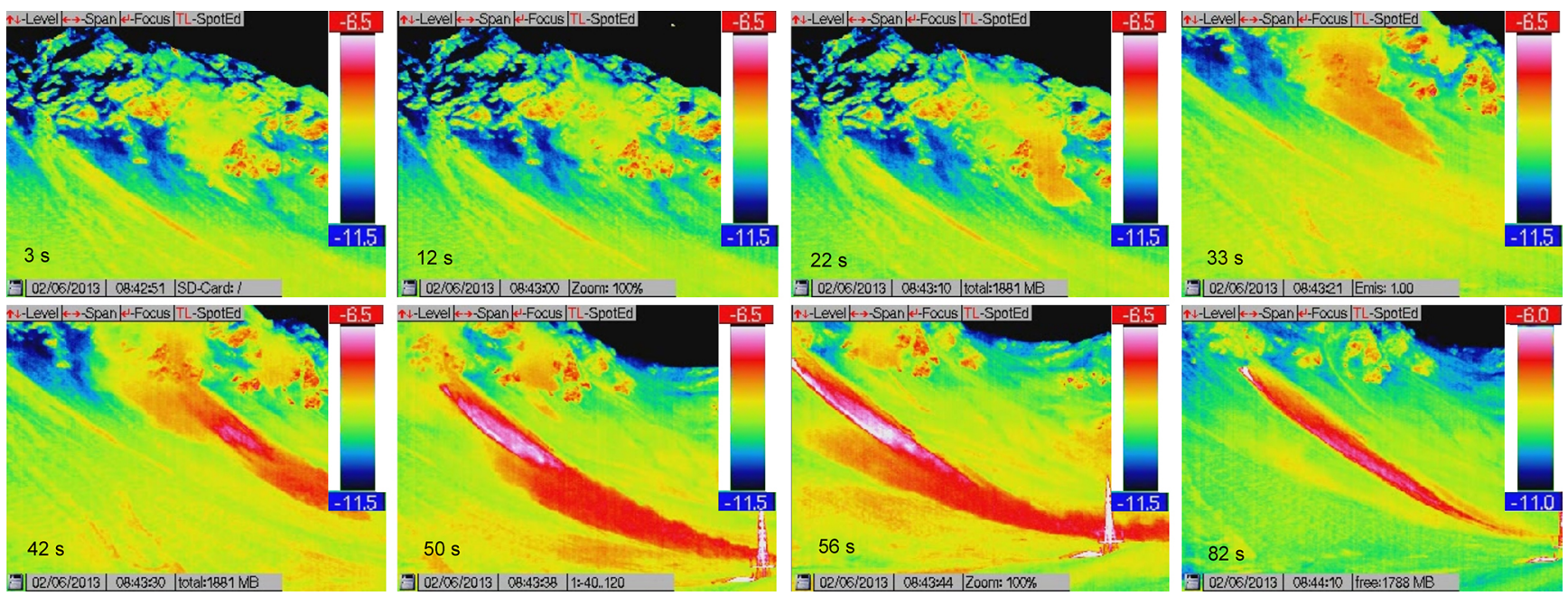

Figure 5. Screenshot of IRT camera videos for avalanche \#2. The first picture was taken $3 \mathrm{~s}$ after the avalanche released. Note that the temperature scale was changed by $0.5^{\circ} \mathrm{C}$ for the last shown image $(82 \mathrm{~s})$.

to the observer's right (north) of the summit resulted in a small powder avalanche which triggered a second slide at the lower end of the rock face (similar to avalanche \#2). Consequently a significant amount of snow was eroded and resulted in a medium-sized avalanche (deposition mass 2120 t) that stopped in the flat run out zone (Fig. 1c). The secondary release nearly entrained all layers to the bottom of the snowpack $(1.6 \mathrm{~m})$. Average snow density of the release was 270 and $310 \mathrm{~kg} \mathrm{~m}^{-3}$ for the entrained snow. For avalanche \#3 snow temperature measurements were also available for the cornice at the ridge.

\section{Results}

Based on these measurements we present observed temperature distributions during the avalanche motion as well as at the surface and inside the deposition zone (Sect. 4.1). In a second step potential sources of thermal energy are identified and quantified (Sect. 4.2).

\subsection{Temperature distribution}

\subsubsection{Avalanches in motion}

The use of the IRT camera gave very interesting qualitative insights into the temperature behaviour of a moving avalanche (Figs. 3 and 5). Especially plume formation, entrainment of warmer snow and the stopping of the avalanche as the powder cloud starved and drifted aside could be very well observed. (See Supplement for the videos).

Even though avalanche \#1a was small, a significant powder cloud developed shortly after the release (Fig. 3). After the avalanche entered the open slope (37 s), plume formation stopped, accompanied by a visible decrease in velocity, and the powder cloud drifted to the uphill-looking right side ( $47 \mathrm{~s}$ ) due to the prevailing wind, revealing the until then obscured dense core $(57 \mathrm{~s})$. After that a rapid cooling of the surface of the dense core could be observed (from pink colours at $57 \mathrm{~s}$ to orange at $77 \mathrm{~s}$ ).

The IRT video of avalanche \#2 (Fig. 5) is of special interest since a distinct acceleration of the avalanche can be observed as it approaches the open slope below the rock face $(33 \mathrm{~s})$. This can be explained by the entrainment of mass of the secondary release $(42 \mathrm{~s})$. The powder cloud shows higher temperatures than during the first phase $(50 \mathrm{~s})$ and the eroded surface becomes visible after the powder cloud drifts aside (56-82 s). Even though continuous IRT images were acquired during and after avalanche \#3 this data could not be used in this study as clouds were preventing an undisturbed view on the slope most of the time.

\subsubsection{Surface temperature distribution}

The IRT camera images acquired shortly after the avalanches stopped (Fig. 6) allowed to identify exposed deep, and thus warmer, layers in the release and along the path as well as in the deposited snow. In Fig. $6 \mathrm{~b}$ the secondary release, below the steep rock part, showed a much deeper erosion in the, looking uphill, left corner. In the lower part of the track erosion was spatially rather homogenous for all avalanches.

Lateral IRT surface temperature transects in the deposition area of avalanche \#1 and \#2 (black lines in Fig. 6) revealed that the warmest part of the avalanche is located in the centre and therefore in its dense core (Fig. 7a and c). In both cases a distinct difference in surface temperature between undisturbed snow cover and warmer core of the avalanche is evident. Figure 7b shows lateral profiles (L1 and L2 in Fig. $6 \mathrm{~b}$ ) along the path of the avalanche. These coincide with in-field measurements of the undisturbed snow cover, a thin- 

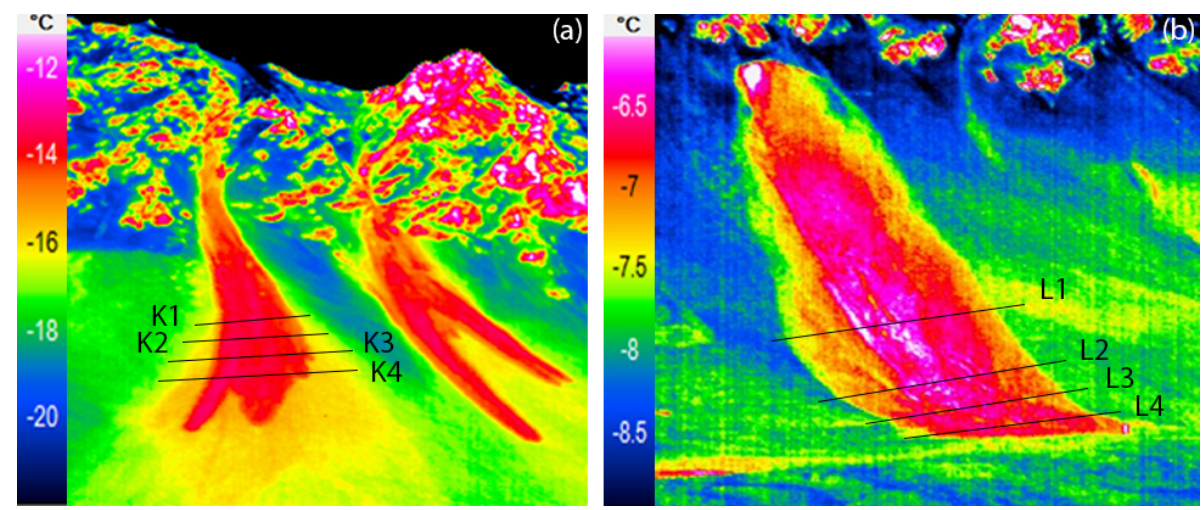

Figure 6. IRT camera images for avalanches (a) \#1a and \#1b and (b) \#2. Note the different temperature scales amongst the avalanches. Black lines indicate positions of lateral snow temperature transects.

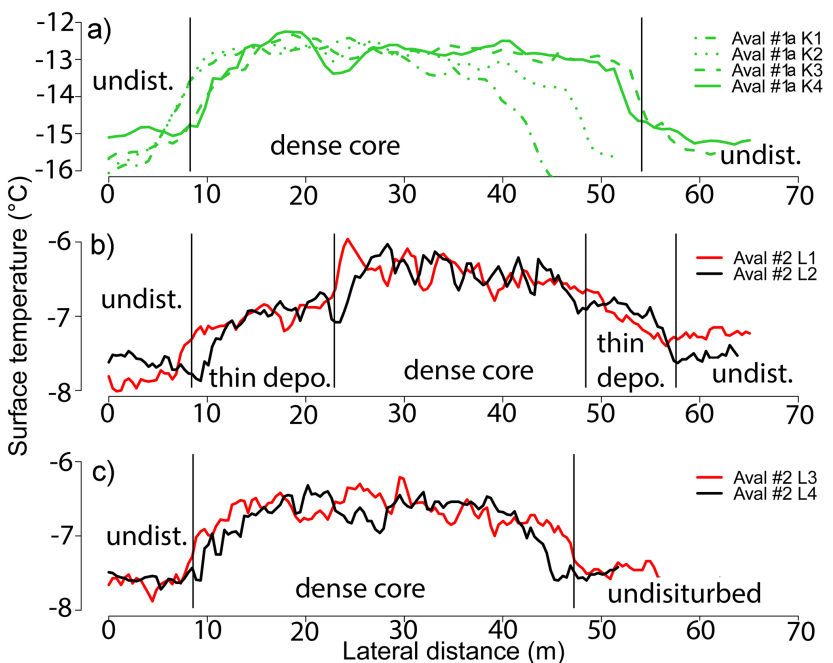

Figure 7. Snow surface temperatures acquired with IRT along lateral transects for avalanche \#1 (a) and in the path (b) and the deposition area (c) of avalanche \#2. Extent of undisturbed snow cover, thin-deposit and dense core are indicated. The lateral distance was calculated by referencing and scaling with the measured width of the avalanche.

deposit layer that formed at the observer's left (south) side of avalanche \#2 and the dense core.

\subsubsection{Internal temperature distribution of deposits}

The observed maximum temperatures in the dense core area did not only exist on the surface in lateral extension (Fig. 7) but also vertically in the deposits. This could be measured for both avalanches for which lateral investigations were conducted. Figure 8 shows the lateral temperature measurements conducted in the deposition zone of avalanche \#2 and \#3. Measurement $P_{\text {depo }}$, corresponding to $0 \mathrm{~m}$, was located in the middle of the deposition and marked the position of the full snow profile in the deposits (Fig. 2). Temperature measurement locations $\mathrm{R}$ and $\mathrm{L}$ were leading laterally from the centre to the, looking uphill, right and left side of the avalanche deposits. Furthermore, the top of the avalanche deposits (solid line), the bottom of the deposits (dashed line) and the terrain (pointed line) are indicated. For better distinction the area of the undisturbed snow cover is additionally indicated by softened colours. Even though the transect shown in Fig. 8a only represents one half of the avalanche deposits from avalanche \#2, the extent of the dense core (area between solid and dashed line) could clearly be observed in the measured snow temperature. Similar measurements were recorded for avalanche \#3 where again the highest temperatures were recorded in the centre of the deposits (Fig. 8b) with decreasing values towards the side of the deposits.

\subsection{Thermal energy sources}

To explain the observed increase in snow temperatures in the deposits of the investigated avalanches and to assign an order of magnitude estimation of the sources of thermal energy, we look at two important sources of energy, namely (i) friction and (ii) warming due to entrainment of snow. Other potential sources of thermal energy, e.g. entrainment of air or adiabatic warming, were not further considered since an order of magnitude estimation revealed that their influence on the temperature of the dense core is negligibly small (not shown).

Figure 9 shows snow temperature profiles in the centre of the deposition zone $T \_P_{\text {depo }}$ (violet line) and compares them to measurements conducted in the release zone $T_{-} P_{\text {release }}$ (blue line), along the path in the undisturbed snow $T_{-} P_{\text {track }}$ (orange) and the undisturbed snow cover in the run out zone $T_{-} P_{\text {runout }}$ (gray). Depth-averaging the deposition profile (solid violet line in Fig. 9) yielded a snow temperature of $-6.8^{\circ} \mathrm{C}$ for avalanche $\# 2$ and $-4.1{ }^{\circ} \mathrm{C}$ for avalanche \#3 $\left(\bar{T} \__{-}{ }_{\text {depo }}\right.$ in Table 2$)$. For $T_{-} P_{\text {depo }}$ the temperature values from the upper and lowermost layers $(0.2 \mathrm{~m}$ thick) were excluded from the calculations because of adaption of the temperature with the surrounding air and undisturbed snow cover 

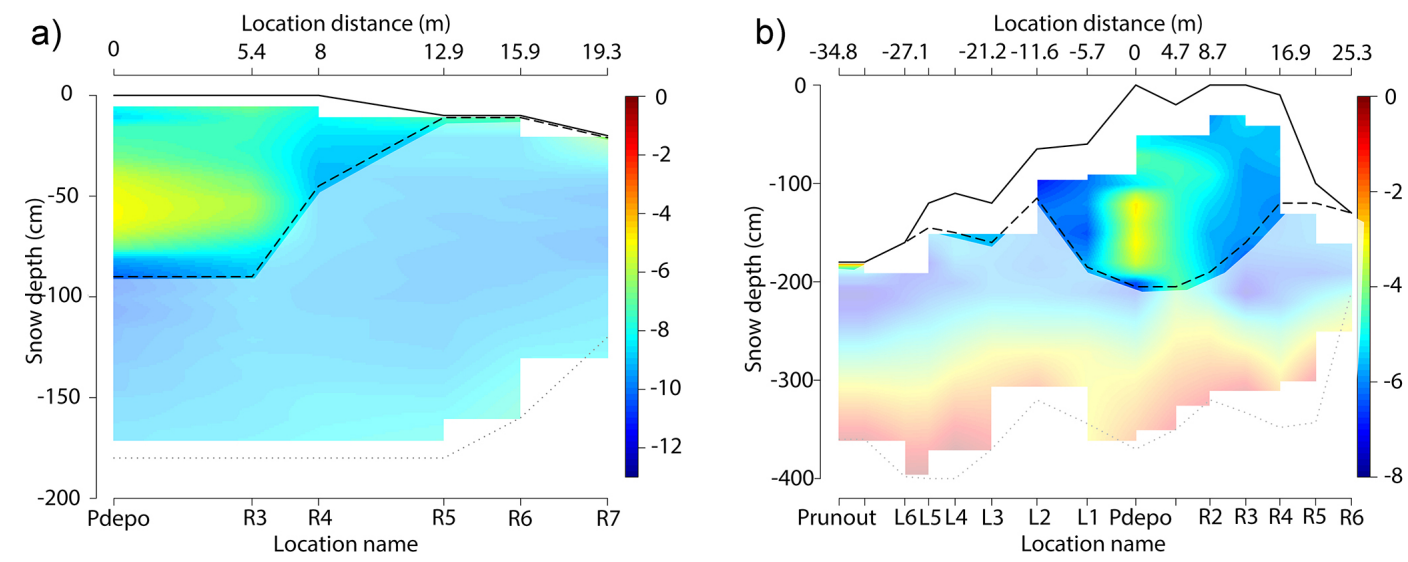

Figure 8. Lateral snow temperature profiles in the avalanche deposits of (a) avalanche $\# 2$ and (b) avalanche \#3. $P_{\text {depo }}$ and $0 \mathrm{~m}$ indicate the centre of deposits and the index "L" and "R" represent left and right, looking uphill, measurement locations towards the lateral sides of the avalanches. Lines indicate the top of the avalanche deposit or snow cover (solid), bottom of avalanche deposit (dashed) and bottom of snow cover (pointed). Colours of undisturbed snow cover were softened for better distinction with avalanche deposits.
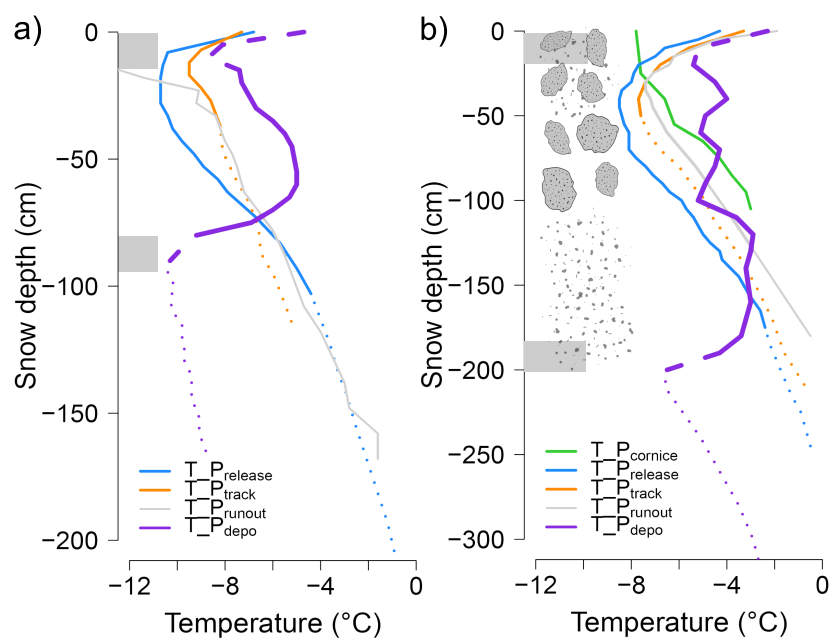

Figure 9. Snow temperature measurements conducted in the undisturbed snow cover close to the release zone $\left(T_{-} P_{\text {release }}\right)$, along the path $\left(T_{-} P_{\text {track }}\right)$ and in the run out zone $\left(T_{-} P_{\text {runout }}\right)$ as well as in the deposition zone $\left(T_{-} P_{\text {depo }}\right)$ of (a) avalanche \#2 and (b) avalanche \#3. Release, entrainment and deposition depths are indicated by solid lines, whereas the undisturbed snow cover is represented by pointed lines. Gray areas and dashed lines indicate parts of the temperature profiles in the deposits $\left(T_{-} P_{\text {depo }}\right)$ that were neglected in the calculations because of expected changes in temperature over time due to the boundary conditions of the surface and the undisturbed snow cover. Composition of deposits (granules and fine grains) are indicated for avalanche \#3.

(gray areas in Fig. 9). Since $\bar{T}_{-} P_{\text {depo }}$ only represents the relatively warm core of the deposits we additionally calculated the mean of the lateral temperature profiles (Fig. 8) re- sulting in a mean temperature of the deposits $\bar{T}_{\text {depo_lateral }}$ of -7.4 and $-4.8^{\circ} \mathrm{C}$ for avalanche $\# 2$ and \#3, respectively.

Comparing the mean temperature of the deposits $\bar{T}_{\text {depo_lateral }}$ with $\bar{T}_{-}{ }_{\text {release }}$ reveals that a significant warming took place. This resulted in a difference in snow temperature between released and deposited snow of $\Delta T 1.2$ and $1.5^{\circ} \mathrm{C}$ for avalanche $\# 2$ and $\# 3$, respectively (Table 2 ).

\subsubsection{Friction}

The increase in temperature due to friction was calculated by assuming that all potential energy is transformed to heat. This means that the increase in temperature is only given by the drop height of the average avalanche mass:

$m c_{p} \Delta T=m g \Delta h$,

where $m$ is the mass undergoing the change in potential energy, $c_{p}$ is the specific heat capacity of snow $\left(2116 \mathrm{~J} \mathrm{~kg}^{-1} \mathrm{~K}^{-1}\right), \Delta T$ is the change in snow temperature, $g$ is the gravitational acceleration $\left(9.81 \mathrm{~m} \mathrm{~s}^{-2}\right)$ and $\Delta h$ is the difference in elevation. Thus, the temperature increase due to friction $\Delta T_{\text {friction }}$ is given by

$\Delta T_{\text {friction }}=\frac{g \Delta h}{c_{p}}$.

This equation has general validity for any (incremental or finite) mass, in which potential energy is converted to heat. This is regardless of whether this mass is added to the avalanche by entrainment or whether it belongs to the initial release mass as long as $\Delta h$ is the effective height drop of this mass. Calculating for an elevation drop of $300 \mathrm{~m}$, corresponding to the slope below the rock face until the run out 
Table 2. Depth averaged temperatures of release $\left(\bar{T}_{-} P_{\text {release }}\right)$, track $\left(\bar{T} \__{-}\right.$track $)$and deposition profile $\left(\bar{T} \__{-}\right.$depo $)$with the corresponding release and erosion depths (in brackets). $\bar{T}_{\text {depo_lateral }}$ represents the mean of the lateral temperature measurements in the deposition. $\Delta T$ is the difference between $\bar{T}_{\text {depo_lateral }}$ and $\bar{T}_{-} P_{\text {release }}$. $\Delta T_{\text {friction }}$ and $\Delta T_{\text {entrainment }}$ are the individual contributions to $\Delta T$.

\begin{tabular}{lll}
\hline Avalanche & $\# 2$ & $\# 3$ \\
\hline $\bar{T}_{-} P_{\text {release }}$ & $-8.6^{\circ} \mathrm{C}(1.03 \mathrm{~m})$ & $-6.3^{\circ} \mathrm{C}(1.75 \mathrm{~m})$ \\
$\bar{T} \__{\text {track }}$ & $-8.7^{\circ} \mathrm{C}(0.37 \mathrm{~m})$ & $-5.8^{\circ} \mathrm{C}(0.3 \mathrm{~m})$ \\
$\bar{T}_{-} P_{\text {depo }}$ & $-6.8^{\circ} \mathrm{C}(0.9 \mathrm{~m})$ & $-4.1^{\circ} \mathrm{C}(1.95 \mathrm{~m})$ \\
$\bar{T}_{\text {depo_lateral }}$ & $-7.4^{\circ} \mathrm{C}$ & $-4.8^{\circ} \mathrm{C}$ \\
\hline$\Delta T$ & $1.2^{\circ} \mathrm{C}$ & $1.5^{\circ} \mathrm{C}$ \\
\hline$\Delta T_{\text {friction }}$ & $0.84^{\circ} \mathrm{C}$ & $0.96^{\circ} \mathrm{C}$ \\
$\Delta T_{\text {entrainment }}$ & $-0.08^{\circ} \mathrm{C}$ & $0.3^{\circ} \mathrm{C}$ \\
\hline
\end{tabular}

zone, we obtain an increase in temperature due to friction of approximately $1.4^{\circ} \mathrm{C}$.

The calculated $\Delta T_{\text {friction }}$ can be seen as an upper limit in our order of magnitude estimation since in nature not all mass is released and entrained at the maximum elevation. Furthermore, lateral temperature gradients in the deposition area are not taken into account. In practice, avalanches entrain large portions of mass along the avalanche path. In many cases the entrained mass, $m_{\mathrm{e}}$, is significantly larger than the released mass, $m_{\mathrm{r}}$. This is also the case for the investigated avalanches which are characterized by a growth index of 3.7 and 1.6 for avalanche \#2 and \#3, respectively. If one further assumes that entrainment is happening uniformly along the path and that the vertical extension of the release area is small compared to the total path vertical drop, the entrained mass only experiences on average half the height drop of the released mass: $\Delta h_{\mathrm{e}}=0.5 \Delta h_{\mathrm{r}}$. The effective $\Delta h$ for Eq. (2) can then be calculated:

$\Delta h=\frac{\Delta h_{\mathrm{r}}\left(m_{\mathrm{r}}+0.5 m_{\mathrm{e}}\right)}{m_{\mathrm{r}}+m_{\mathrm{e}}}$.

For avalanche \#2 and \#3 this corresponds to a warming due to friction, $\Delta T_{\text {friction, }}$ of 0.84 and $0.96^{\circ} \mathrm{C}$, respectively.

\subsubsection{Entrainment at a different temperature}

The above development assumes that there is no difference between initial snow temperatures of the released and entrained snow. The snow profiles (see locations in Fig. 2) enabled a quantification of the properties of the released and entrained snow showing some difference as discussed above. Assuming that the snow that is entrained along the track is completely mixed with the released snow in the deposition zone results in the mean temperature difference between entrained $\left(\bar{T} \__{-}{ }_{\text {track }}\right)$ and released snow $\left(\bar{T} \__{-}\right.$release $)$. This difference leads to the following difference in temperature at the deposited snow mass:
$\Delta T_{\text {entrainment }}=\frac{\left({\bar{T} \_P_{\text {track }}}-{\left.\bar{T} \_P_{\text {release }}\right)}_{m_{\mathrm{e}}}\right.}{m_{\mathrm{r}}+m_{\mathrm{e}}}$.

This results in a change in temperature due to entrainment $\Delta T_{\text {entrainment }}$ of $-0.080 .3^{\circ} \mathrm{C}$ for avalanche \#2 and \#3, respectively. Since we assume that the heating due to friction is independent of the initial snow temperature either from release or entrainment, at least as long as the snow remains dry during warming, the temperature change due to a different snow temperature of the entrained snow can simply be added to the one from friction in Eq. (2).

\section{Discussion}

It has been noted in other studies (Vera et al., 2012) that potential sources of thermal energy in snow avalanches are friction processes or entrainment of snow with differing temperatures. The investigated avalanches in this study indicate that the thermal energy increase was mainly defined by frictional heating, which in turn depends only on the effective elevation drop (Sect. 4.2.1). Yet, it is well known that avalanches can significantly increase their mass along the path via entrainment (Sovilla et al., 2006). Also for the investigated avalanches the growth index were $I_{\mathrm{g}}$ of 3.7 and 1.6 for avalanche \#2 and \#3, respectively. Therefore, the calculated (maximum) value of approximately $0.46^{\circ} \mathrm{C}$ per 100 altitudinal metres (Eq. 2) has to be adapted to consider the actual mass that enters the avalanche at a certain point along the track (Sect. 4.2). For dry and cold snow avalanches far away from the melting point, the warming due to friction alone is not expected to have a substantial influence on flow dynamics. Yet, if the overall avalanche temperature is already close to the critical temperature threshold of $-1{ }^{\circ} \mathrm{C}$ (Steinkogler et al., 2015) the warming by frictional processes can cause drastic changes of the granular structure inside the avalanche and consequently affect flow behaviour.

Contrarily, the warming due to entrainment varied for the individual avalanches. These variations depend on the temperature of the snow and the erosion depth as shown in the profiles along the avalanche track (Fig. 9) and the IRT pictures (Fig. 6). Typically, the alpine snow cover shows a positive temperature gradient towards the ground (Armstrong and Brun, 2008). Except for areas with permanent permafrost, the temperature at the soil-snow interface can be assumed to be approximately $0^{\circ} \mathrm{C}$ if there has been a significant snow cover for several weeks. Consequently, the erosion of deeper snow layers leads to warmer snow temperatures (Fig. 9). Also changes of snow temperature due to elevation gradients have been proven to be quite variable and directly influence flow dynamics (Steinkogler et al., 2014). As in the case of avalanche \#2 even a cooling of an avalanche is possible when the avalanche released into deep layers but entrained only superficial (cold) layers of snow, e.g. blue and orange lines in Fig. 9. Overall, the contribution of the temperature 
of the entrained snow to the temperature change was smaller than by friction for the investigated avalanches (Table 2).

Our temperature measurements on the surface (Fig. 7) and in depth (Fig. 8) of the deposit indicate that the highest temperatures are located in the dense core of the avalanche. The interface between the bottom of the avalanche deposits and the subjacent undisturbed snow cover featured a very clear and sharp transition (violet lines in Fig. 9). The shape of the temperature curve indicates the warmest temperatures in the lower parts of the deposits profile $(-0.4$ to $-0.8 \mathrm{~m}$ and -1.2 to $-1.9 \mathrm{~m}$ for avalanches \#2 and \#3, respectively) and close to the sliding surface. This would support the expectation of the most pronounced friction at the bottom of the flow, typical for this kind of avalanche. Unfortunately, a cooling of the lowest deposition layers to the temperature of the subjacent undisturbed snow cover has to be expected and thus prevents a definite conclusion on this observation. Also, whether the small temperature variations in the upper part of the deposition profile between 0 and $-1 \mathrm{~m}$ of avalanche \#3 (violet line in Fig. 9) are a result of a mixture of broken parts of the eroded snow cover, with varying temperatures, and formed granules could not be fully answered. Yet, granules embedded in fine grained snow were still clearly observable in this area of the deposition.

It is without question that reaching the deposits after an avalanche release to measure the snow surface temperature with traditional methods, e.g. thermometers, takes too long and the surface as well as the upper most layers would have changed their temperature already. It could be observed in the video of avalanche \#1 (see Supplement) that right after the dense core stopped it started to cool. In all those cases for which a real-time measurement is necessary, IRT technology provides a valuable addition to traditional measurements. Even though in our study we only applied the IRT camera in a qualitative way, the presented basic verification (Fig. 4) with manually measured snow surface temperatures showed a fairly good agreement with an accuracy of about $\pm 1.5^{\circ} \mathrm{C}$. Although further investigations are necessary to define whether absolute values of surface temperature can be acquired without significant uncertainties, the relative accuracy of the IRT cameras are usually high, around $0.05^{\circ} \mathrm{C}$ in our case as specified by the manufacturer. This facilitates tracking relative changes in temperatures even if the absolute value might not be accurate.

Recently IRT was mainly tested and evaluated for snow profile applications at short distances (Schirmer and Jamieson, 2014). Dozier and Warren (1982) investigated the effect of viewing angle on the infrared brightness temperature of snow and found differences of up to $3^{\circ} \mathrm{C}$. Similar values have been found by Hori et al. (2013), yet they concluded that for viewing angles less than $40^{\circ}$ from the nadir, the error in temperature is less than $-0.8^{\circ} \mathrm{C}$. The effect of moisture has been studied extensively (Wu et al., 2009, and references therein), basically concluding that the presence of water causes a strong absorbance and consequently a de- crease in reflectance in the near-infrared spectra of soils. In general, low signal attenuation can be expected for (peak) winter month atmospheres, especially for clear sky conditions, due to relatively low humidity levels. An effect that still illustrates challenges for the interpretation of IRT images is due to the roughness of the investigated surface ( $\mathrm{Wu}$ et al., 2009). In most studies, it is assumed that the scene elements are isothermal, smooth and homogenous (Danilina et al., 2006). Consequently supposing that the object of interest is Lambertian, i.e. behaves as a perfect diffuser and emits and reflects radiation isotropically. Mushkin et al. (2007) observed that the effective emissivity spectra of rough surfaces are different from those of perfectly smooth surfaces of the same composition due to multiple scattering among roughness elements. Yet, they only found an up to $3 \%$ reduction in the spectral contrast due to sub-pixel surface roughness variations. This might also be the case for situations similar to the presented application as size of the granules, i.e. the sub pixel structures, are much smaller than the pixel size ( 0.5 to $1 \mathrm{~m})$.

Also whether the surface temperature, and possibly even the composition, of the aerosol mixture of the powder cloud can be measured is an open question. Visualization of air flows on the qualitative level is common practice for various applications (Narayanan et al., 2003; Carlomagno and Cardone, 2010) and, as presented in this study, provides impressive footage of powder snow avalanches. Usually a tracer is injected into the flow field. In our case the tracer is already present by snow particles of the entrained snow which are transported into the powder cloud.

A possible further application of IRT could be the differentiation of flow regimes in the deposition area. As shown earlier the warmest part of an avalanche is located in the dense core, e.g. center (red and pink) of avalanche \#2 in Fig. $6 \mathrm{~b}$, whereas layers with less mass or where less friction occurred are cooler (yellow and orange areas in Fig. 6b). Especially the observer's left (south) side thin-deposit area in Fig. $6 \mathrm{~b}$ might be associated with the deposits of a fluidized layer (Issler et al., 2008). The IRT observations of this thindeposit area are in agreement with the field observation criteria for fluidized layers as described by Issler et al. (2008): (1) rapid decrease of deposit thickness, (2) snowballs of various sizes embedded in a matrix of compacted fine-grained snow, (3) large snowballs lying on top of the deposit and (4) fewer snowballs per unit area than on the dense deposit.

The powder clouds of the investigated avalanches (see Figs. 3 and 5 and corresponding videos) had consistently lower temperatures than the warm dense core despite the fact that the powder cloud (at least from one avalanche) travelled as far downhill as the dense core. Two distinct processes may contribute to this fact: (i) a preferential ejection of colder and lighter surface with colder snow while the dense core may have a higher fraction of snow from lower layers in the profile and therefore with a higher temperature. (ii) The particle concentration in the suspension layer is low and therefore 
molecular dissipation of kinetic energy and exchange of sensible and latent heat happens largely between air and snow and not between snow and snow particles as in the dense core. This leads to a rapid adoption of temperatures close to the air temperature for the suspended snow.

Furthermore, the IRT results can be qualitatively interpreted in a similar way as a laser scan to identify areas where deeper or shallower erosion occurred, e.g. see entrainment by secondary release below the rock face for avalanche \#2 (Fig. 6b). For this avalanche, we (for the sake of example) calculated the release mass solely by using information from the IRT pictures and manually measured snow profiles in the release. Therefore, the IRT picture was georeferenced in a GIS software and shallower and deeper release layers were identified. The (IRT) surface temperature of these layers were combined with the snow height of the corresponding temperature in the conducted snow profile in the release. This resulted in a calculated release mass of $457 \mathrm{t}$, which is similar to the mass measured with the terrestrial laser scan $(502 t)$. This depicts a rough yet quick and efficient method to estimate the release mass of an avalanche. As shown in this study, the release and entrainment depth does not only define the overall mass of snow but equally important its temperature. IRT pictures and videos provide an intuitive and easy way to identify these relevant erosion processes (Fig. 6).

\section{Conclusions}

We conducted full-scale avalanche experiments at the Flüelapass field site above Davos (Switzerland) to investigate the distribution of snow temperatures in avalanche deposits and identify the sources of thermal energy in dry avalanches. A further goal was to test the usability of infrared radiation thermography (IRT) in this context.

For the investigated similar avalanches the temperature increase due to friction has been shown to dependent on the effective elevation the mass inside the avalanche dropped. The contribution to the total temperature increase by erosion processes was shown to be quite variable, depending on the release depth and snow temperatures of the entrained snow. The warmest temperatures were observed in the centre of the avalanche deposits and thus represented the dense core of the flowing avalanche.

The IRT camera allowed to observe the avalanche phenomenon "with different eyes" and provides a lot of potential for more detailed research in the field of avalanche dynamics, both quantitative and qualitative. It is still necessary to further verify the measurements and define to which extent absolute snow surface temperatures can be measured. Then, the spatial distribution of surface temperatures can help in the interpolation of profile temperatures measured by hand.

Our results allow for a more comprehensive understanding of snow temperatures in avalanche flow and their consequences on flow regimes. This information can directly be used to verify and enhance the performance of avalanche dynamics models and is thus of great interest for practitioners.

\section{The Supplement related to this article is available online at doi:10.5194/tc-9-1819-2015-supplement.}

Acknowledgements. Funding for this research has been provided through the Interreg project STRADA and STRADA 2 by the following partners: Amt für Wald Graubünden, Etat du Valais, ARPA Lombardia, ARPA Piemonte, Valle d'Aosta, Regione Lombardia. The authors would like to thank all the people who helped gathering the data during the field experiments and Perry Bartelt for his valuable input. Thanks to Vali Meier from the SOS Service Jakobshorn (Davos) and his team for the great support. We thank the anonymous reviewers and the editor who helped to significantly improve the quality of the paper.

Edited by: F. Dominé

\section{References}

Armstrong, R. L. and Brun, E.: Snow and Climate: Physical Processes, Surface Energy Exchange and Modeling, Cambridge University Press, Cambridge, UK, 222 pp., 2008.

Bartelt, P., Bühler, Y., Buser, O., Christen, M., and Meier, L.: Modeling mass-dependent flow regime transitions to predict the stopping and depositional behavior of snow avalanches, J. Geophys. Res., 117, F01015, doi:10.1029/2010JF001957, 2012.

Bates, B., Ancey, C., and Busson, J.: Visualization of the internal flow properties and the material exchange interface in an entraining viscous Newtonian gravity current, Environ. Fluid Mech., 14, 501-518, 2014.

Brenning, A., Gruber, S., and Hoelzle, M.: Sampling and statistical analyses of BTS measurements, Permafrost Periglac. Process., 16, 383-393, 2005.

Bühler, Y., Marty, M., Egli, L., Veitinger, J., Jonas, T., Thee, P., and Ginzler, C.: Snow depth mapping in high-alpine catchments using digital photogrammetry, The Cryosphere, 9, 229243, doi:10.5194/tc-9-229-2015, 2015.

Carlomagno, G. and Cardone, G.: Infrared thermography for convective heat transfer measurements, Exp. Fluids, 49, 1187-1218, doi:10.1007/s00348-010-0912-2, 2010.

Danilina, I., Mushkin, A., Gillespie, A., O’Neal, M., Pietro, L., and Balick, L.: Roughness effects on sub-pixel radiant temperatures in knetically isothermal surfaces, in: RAQRS II: 2nd International Symposium on Recent Advances in Quantitative Remote Sensing, 25-29 September 2006, Torrent (Valencia), Spain, 2006.

Dozier, J. and Warren, S. G.: Effect of viewing angle on the infrared brightness temperature of snow, Water Resour. Res., 18, 14241434, doi:10.1029/WR018i005p01424, 1982.

Fierz, C., Armstrong, R., Durand, Y., Etchevers, P., Greene, E., McClung, D., Nishimura, K., Satyawali, P., and Sokratov, S.: The international classification for seasonal snow on the ground, IHPVII Technical Documents in Hydrology No. 83, IACS Contribution No. 1, UNESCO-IHP, Paris, 2009. 
Gauer, P., Issler, D., Lied, K., Kristensen, K., and Sandersen, F.: On snow avalanche flow regimes: inferences from observations and measurements, paper presented at International Snow Science Workshop ISSW 2008, Whistler, Canada, 717-723, 2008.

Hori, M., Aoki, T., Tanikawa, T., Hachikubo, A., Sugiura, K., Kuchiki, K., and Niwano, M.: Modeling angular-dependent spectral emissivity of snow and ice in the thermal infrared atmospheric window, Appl. Optics, 52, 7243-7255, doi:10.1364/AO.52.007243, 2013.

Issler, D., Errera, A., Priano, S., Gubler, H., Teufen, B., and Krummenacher, B.: Inferences on flow mechanisms from snow avalanche deposits, Ann. Glaciol., 49, 187-192, 2008.

Lewkowicz, A. G. and Ednie, M.: Probability mapping of mountain permafrost using the BTS method, Wolf Creek, Yukon Territory, Canada, Permafrost Periglac. Process., 15, 67-80, 2004.

Meola, C. and Carlomagno, G. M.: Recent advances in the use of infrared thermography, Meas. Sci. Technol., 15, 9, 2004.

Mushkin, A., Danilina, I., Gillespie, A. R., Balick, L. K., and McCabe, M. F.: Roughness effects on thermal-infrared emissivities estimated from remotely sensed images, in: Remote Sensing, International Society for Optics and Photonics, 67492V-67492V, 2007.

Naaim, M., Durand, Y., Eckert, N., and Chambon, G.: Dense avalanche friction coefficients: influence of physical properties of snow, J. Glaciol., 59, 771-782, doi:10.3189/2013JoG12J205, 2013.

Narayanan, V., Page, R., and Seyed-Yagoobi, J.: Visualization of air flow using infrared thermography, Exp. Fluids, 34, 275-284, 2003.

Schirmer, M. and Jamieson, B.: Limitations of using a thermal imager for snow pit temperatures, The Cryosphere, 8, 387-394, doi:10.5194/tc-8-387-2014, 2014.

Shea, C. and Jamieson, B.: Some fundamentals of handheld snow surface thermography, The Cryosphere, 5, 55-66, doi:10.5194/tc-5-55-2011, 2011.
Shea, C., Jamieson, B., and Birkeland, K. W.: Use of a thermal imager for snow pit temperatures, The Cryosphere, 6, 287-299, doi:10.5194/tc-6-287-2012, 2012.

Snyder, W. C., Wan, Z., Zhang, Y., and Feng, Y.-Z.: Classificationbased emissivity for land surface temperature measurement from space, Int. J. Remote Sens., 19, 2753-2774, doi:10.1080/014311698214497, 1998.

Sovilla, B., Burlando, P., and Bartelt, P.: Field experiments and numerical modeling of mass entrainment in snow avalanches, J. Geophys. Res.-Earth, 111, F03007, doi:10.1029/2005JF000391, 2006.

Sovilla, B., Margreth, S., and Bartelt, P.: On snow entrainment in avalanche dynamics calculations, Cold Reg. Sci. Technol., 47, 69-79, doi:10.1016/j.coldregions.2006.08.012, 2007.

Sovilla, B., McElwaine, J. N., Schaer, M., and Vallet, J.: Variation of deposition depth with slope angle in snow avalanches: Measurements from Vallee de la Sionne, J. Geophys. Res.-Earth, 115, F02016, doi:10.1029/2009JF001390, 2010.

Steinkogler, W., Sovilla, B., and Lehning, M.: Influence of snow cover properties on avalanche dynamics, Cold Reg. Sci. Technol., 97, 121-131, doi:10.1016/j.coldregions.2013.10.002, 2014

Steinkogler, W., Gaume, J., Löwe, H., Sovilla, B., and Lehning, M.: Granulation of snow: from tumbler experiments to discrete element simulations, J. Geophys. Res.-Earth, in press, 2015.

Vera, C., Feistl, T., Steinkogler, W., Buser, O., and Bartelt, P.: Thermal Temperature in Avalanche Flow, paper presented at International Snow Science Workshop ISSW 2012, Anchorage, Alaska, 32-37, 2012.

Vera Valero, C., Wikstroem Jones, K., Bühler, Y., and Bartelt, P.: Release temperature, snow-cover entrainment and the thermal flow regime of snow avalanches, J. Glaciol., 61, 173-184, 2015.

Wu, C.-Y., Jacobson, A. R., Laba, M., and Baveye, P. C.: Accounting for surface roughness effects in the near-infrared reflectance sensing of soils, Geoderma, 152, 171-180, doi:10.1016/j.geoderma.2009.06.002, 2009. 